\title{
Exome sequencing identifies somatic point mutations associated with acquired endocrine resistance in breast cancer cell lines
}

\author{
Natasja S Ehlers ${ }^{1,2^{*}}$, Zhu Shi Da ${ }^{1,3}$, Daniel Elias ${ }^{1,4}$, Xue Lin ${ }^{1,3}$, Jian Li ${ }^{1,3,5}$, Christina Bjerre ${ }^{1,6}$, Nils Brunner ${ }^{1,6}$, \\ Lars Bolund ${ }^{1,3,5}$, Wang Jun ${ }^{1,3}$, Ramneek Gupta ${ }^{1,2}$, Henrik J Ditzel ${ }^{1,3}$
}

From Beyond the Genome 2012

Boston, MA, USA. 27-29 September 2012

\section{Background}

Endocrine therapy is an effective treatment of estrogen receptor-positive $(E R+)$ breast tumors, significantly reducing mortality. However, approximately $30 \%$ of patients receiving adjuvant endocrine therapy will experience recurrence within a 15 -year period. The mechanisms of endocrine resistance are poorly understood. Understanding the underlying genetic diversity of breast cancers responding differently to endocrine therapy is important for the development of more optimal and individualized treatments strategies.

\section{Materials and methods}

In the current study, a panel of isogenic MCF-7-derived human breast cancer cell lines [1-3] that are resistant to tamoxifen only, or to both tamoxifen and fulvestrant, respectively, were analyzed for mutations through exome sequencing and compared with the exome of the parental cell line. In addition, global gene expression levels for the same panel of cell lines were generated. Detected variations were integrated with gene expression profiles and analyzed in the context of prior knowledge of drug action and genes associated with resistance to endocrine therapies as identified by extensive literature curation.

\section{Results and conclusion}

A small panel of somatic point mutations potentially associated with acquired endocrine resistance were identified. Future experimental validation will reveal which of the detected mutations that are causatively involved in resistance to endocrine therapy.

\section{Author details}

${ }^{1}$ Sino-Danish Breast Cancer Research Centre. ${ }^{2}$ Center for Biological Sequence Analysis, Department of Systems Biology, Technical University of Denmark, Building 208, DK-2800 Kongens Lyngby, Denmark. ${ }^{3}$ BGI-Shenzhen, Beishan Industrial Zone, Yantian District, Shenzhen 518083, China. ${ }^{4}$ Department of Cancer and Inflammation Research, Institute of Molecular Medicine, University of Southern Denmark, Winslowsvej 25, DK-5000 Odense, Denmark. ${ }^{5}$ Department of Human Genetics, Aarhus University, Wilhelm Meyers Allé 4, DK-8000 Aarhus C, Denmark. ${ }^{6}$ Section for Pathobiology, Department of Veterinary Disease Biology, Faculty of Life Sciences, University of Copenhagen, Dyrlægevej 88, I. DK-1870 Frederiksberg C, Denmark.

Published: 1 October 2012

\section{References}

1. Brunner N, Boulay V, Fojo A, Freter CE, Lippman ME, Clarke R: Acquisition of hormone-independent growth in MCF-7 cells is accompanied by increased expression of estrogen-regulated genes butwithout detectable DNA amplifications. Cancer Res 1993, 53:283-290.

2. Brunner N, Frandsen TL, Holst-Hansen C, Bei M, Thompson EW, Wakeling AE, Lippman ME, Clarke R: MCF7/LCC2: a 4-hydroxytamoxifen resistant human breast cancer variant that retains sensitivity to the steroidal antiestrogen ICI 182,780. Cancer Res 1993, 53:3229-3232.

3. Brunner N, Boysen B, Jirus S, Skaar TC, Holst-Hansen C, Lippman J, Frandsen T, Spang-Thomsen M, Fugua SA, Clarke R: MCF7/LCC9: an antiestrogen-resistant MCF-7 variant in which acquired resistance to the steroidal antiestrogen ICI 182,780 confers an early cross-resistance to the nonsteroidal antiestrogen tamoxifen. Cancer Res 1997, 57:3486-3493.

doi:10.1186/1753-6561-6-S6-P35

Cite this article as: Ehlers et al.: Exome sequencing identifies somatic point mutations associated with acquired endocrine resistance in breast cancer cell lines. BMC Proceedings 2012 6(Suppl 6):P35.

${ }^{1}$ Sino-Danish Breast Cancer Research Centre

Full list of author information is available at the end of the article

(c) 2012 Ehlers et al; licensee BioMed Central Ltd. This is an Open Access article distributed under the terms of the Creative Commons 